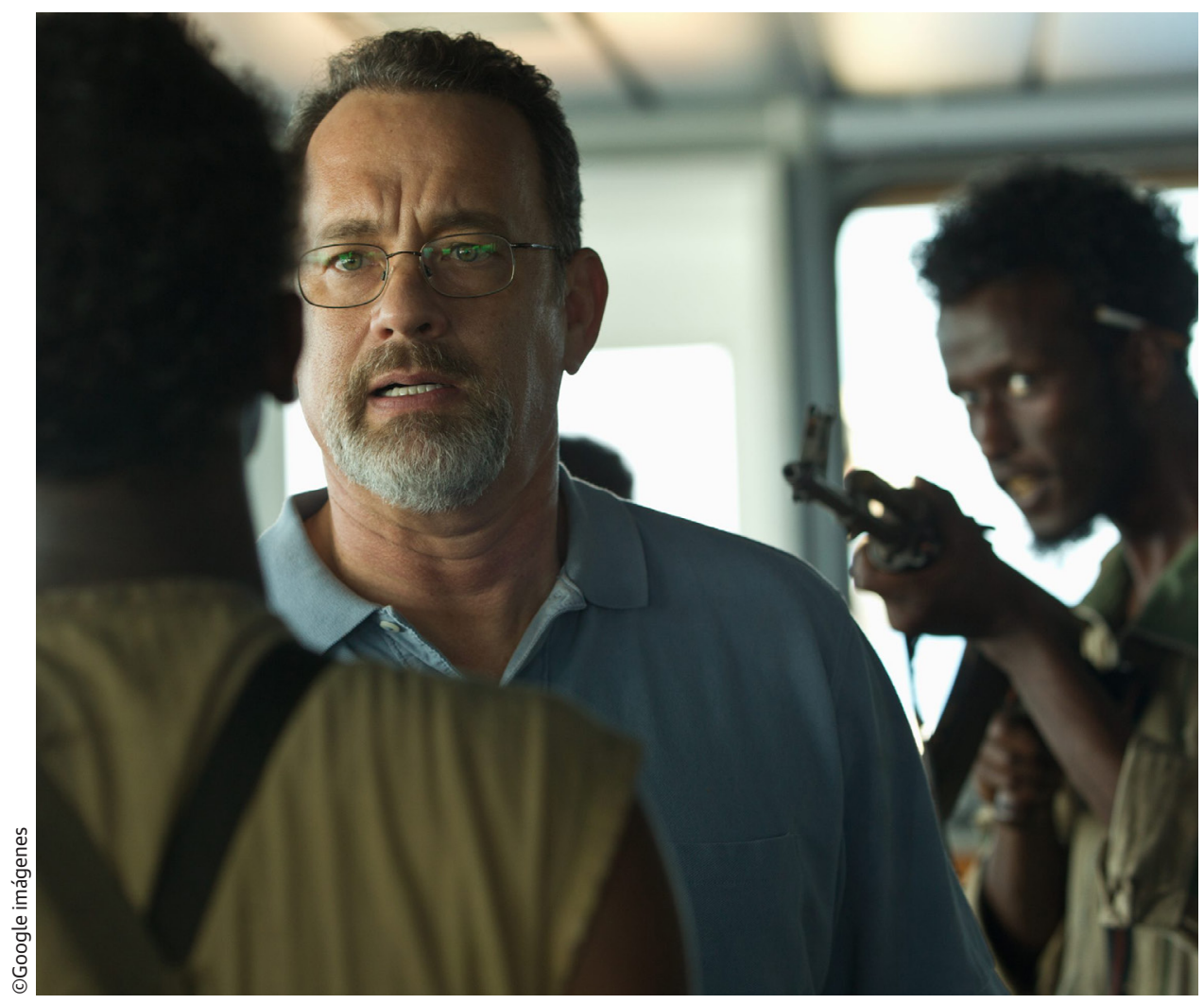

\title{
COLONIALISMO, INCONSCIENTE POLÍTICO Y CARTOGRAFÍA COGNITIVA EN EL ESPACIO DEL FILME “CAPITÁN PHILLIPS”
}

COLONIALISM, POLITICAL UNCONSCIOUS AND COGNITIVE MAPPING IN THE SPACE OF THE FILM "CAPTAIN PHILLIPS"

Alberto González Pascual / agonzalezp@prisa.com UNIVERSIDAD REY JUAN CARLOS 


\title{
RESUMEN
}

El propósito de este artículo es describir mediante un análisis marxista del filme estadounidense Capitán Phillips (Paul Greengrass, 2013), basado en hechos reales, cómo la evolución del capitalismo sigue consolidando en los países occidentales la creencia reificada en una superioridad histórica y geográfica de su modelo político y socioeconómico con respecto a los modelos de los países menos desarrollados de África y Asia. Al mismo tiempo, por medio de categorías como la dialéctica materialista, la revisión del difusionismo y la aplicación de la cartografía cognitiva sobre grandes espacios geopolíticos localizados en áreas pobres del mundo, se realiza una interpretación crítica sobre cómo se está articulando actualmente el inconsciente político de la clase trabajadora. Por un lado, en los países ricos y, por otro, sobre cómo se está asentando en los países pobres, estableciéndose una relación entre la representación ideologizada que adquiere un individuo de la realidad histórica en la que existe (en una escala que se mueve desde lo local hasta lo global), y la restricción de su capacidad cognitiva con el fin de evadirse a la hora de realizar una crítica profunda de lo que sucede en su entorno desde múltiples perspectivas. Finalmente, a través de los espacios físicos captados en el filme, se realiza una crítica materialista del proceso comercial mundializado que tiene lugar por medio del transporte marítimo de mercancías, perfilando espacial y cognitivamente los límites de la mentalidad de nuestra época, tanto entre los "ganadores" como entre los “perdedores”, en base al movimiento espacial del capital.

PALABRAS CLAVE

Materialismo histórico, teoría crítica, colonialismo, ideología, marxismo, inconsciente político

\begin{abstract}
The purpose of this article has been made through a Marxist analysis of the US film "Captain Phillips" (Paul Greengrass, 2013), based on a true story. I have found how the evolution of capitalism in the West continues to consolidate the belief reified in a historical and geographical superiority of the political and socioeconomic western models regarding Africa and Asia lowers models. At the same time, through categories like dialectical materialism, criticism of diffusionist theory and application of cognitive mapping to large geopolitical spaces located in most poor areas of the world, I have realized a remark about currently being articulating the political unconscious of working class in rich countries and the poor in poor countries, establishing a relationship between the ideological representation that takes an individual from his historical reality (on a scale that moves from local to global), and how he has developed a mental ability to escape of the responsibility to make a critical review of what's happening around him in all areas. Finally, through physical space captured in the film, I have realized a materialist critique of globalized business process that takes place through the carriage of goods, outlining spatial and cognitively limits of the mentality of our time, both among "winners"as among the "losers", based on the spatial movement of capital.
\end{abstract}

KEYWORDS

Historical materialism, critical theory, colonialism, ideology, Marxism, political unconscious

Recibido: 1 de febrero de 2015

Aceptado: 24 de abril de 2016 


\section{LA VISIÓN COLONIZADORA: EL DIFUSIONISMO Y EL MOTOR DE LA HISTORIA}

El filme Capitán Phillips ${ }^{1}$, dirigido por Paul Greengrass en 2013, brinda una oportunidad para realizar un análisis pluridisciplinar de la reconstrucción cultural, política y económica de la realidad que muestra -para lo que se ha aplicado el método del materialismo histórico de Marx-, pero enriquecido mediante el uso de otras categorías relacionadas con la geografía crítica, la antropología evolutiva y la psicología colectiva, con el fin de no caer en un determinismo mecanicista carente de los suficientes recursos para desmadejar los factores complejos, y a la par contradictorios, que provocan que el capitalismo se mueva constantemente hacia delante, expandiéndose siempre con ventaja.

El argumento del filme está basado en hechos reales. El guion (adaptación de la novela homónima escrita por el propio protagonista, Richard Phillips, A Captain's Duty: Somali Pirates, Navy SEALS, and Dangerous Days at Sea) narra el secuestro de un carguero de gran tonelaje, el Alabama, con bandera de Estados Unidos, que tuvo lugar en 2009, perpetrado por piratas de origen somalí en la zona del cuerno de África, centrándose, a partir del tercer acto, en la operación de rescate que ejecutaron las fuerzas especiales estadounidenses para liberar al capitán.

Antes de diseccionar las diferentes partes que constituyen la estructura de la película, es necesario plantear el contexto filosófico, geográfico y cultural en el que se pretende situar la crítica ideológica y estética. Uno de los propósitos principales de este artículo es poner en práctica el proceso interpretativo de integrar la teoría (marco conceptual) y la praxis (la aplicación de aquella sobre el objeto de análisis para filtrar "descubrimientos" pluridisciplinares; excediendo los límites de la pura especificidad del texto cinematográfico) y que dicha integración se produzca de un modo dinámico a lo largo del texto. Para dar curso a la investigación se em- pieza revisando el proceso de construcción de la ideología colonialista occidental, en cuyo epicentro se sitúa el difusionismo.

Cuando surge una idea en el núcleo de una comunidad humana y logra sedimentarse en la lógica cultural de sus miembros, ocupando un lugar entre aquello que se considera útil para su reproducción (ya sea una herramienta para labrar la tierra, una concepción artística o la cura de una enfermedad), se está designando una invención cuyo origen reside intrínsecamente en esa comunidad o, dicho de otro modo, habría surgido de un modo independiente a cualquier otra zona del mundo. Sin embargo, cuando designamos la adopción por parte de una comunidad específica de una idea que ha sido creada anteriormente por otra comunidad diferente, surge la noción de difusionismo (Blaut, 1977). Esta perspectiva de tradición racionalista considera que la autonomía de la invención es un fenómeno raro, y que lo que ha prevalecido la mayoría del tiempo ha sido siempre la imitación o el seguimiento a ciertos sistemas de ideas e invenciones ya existentes, que son reconocidas socialmente por el éxito o la ventaja que aportan para la supervivencia y la dominación de la naturaleza. El difusionismo, además, va mucho más allá. Para empezar, asume dos axiomas:

\footnotetext{
"1) La mayoría de las comunidades humanas son incapaces de inventar.

2) Unas pocas comunidades humanas (o lugares, o culturas) son inventoras y se mantienen como centros permanentes de cambio cultural, de progreso. A escala global, esto les proporciona un modelo del mundo con un centro -fundamentalmente, la grandísima Europa- y una única periferia" (Blaut, 1993, 14).
}

\footnotetext{
1 El filme fue distribuido por Sony-Columbia. Estrenado en octubre de 2013, su exhibición en salas comerciales se mantuvo hasta marzo de 2014. Con un presupuesto aproximado de 55 millones de dólares, recaudó en taquilla 218,7 millones de dólares -192 millones de euros- (el $49 \%$ en EEUU y el $51 \%$ en el resto del mundo). Obtuvo un recibimiento notable por parte de la crítica especializada, así como por el gremio industrial estadounidense (tuvo 6 nominaciones a los premios Óscar). Fuentes consultadas: boxofficemojo, IMBD.
} 
Ahí se encuentra sintetizada la base de un mundo dividido en dos grandes áreas, Occidente (Europa y Estados Unidos) o el área "Inside", y todo aquello que no es Europa ni Estados Unidos, esto es, el área “Outside”. Lo que yace en el fondo de esta mentalidad que se transmite desde el siglo XIX (momento en el que el difusionismo impone con más fuerza sus criterios) hasta nuestros días, radica en que Europa y EEUU han sido y son considerados los centros principales de producción de la modernidad, el avance social y el cambio tecnológico. Bajo tal concepción se articula una verdad violentamente forzada: dicho binomio es capaz de cambiar, de transformarse, porque tiene naturaleza histórica. Por el contrario, todo lo que permanece fuera de sus límites no cambia, no puede aspirar a la autonomía y la evolución porque es ahistórico. Dicho de otro modo, todo lo que se halla "afuera" no posee los valores europeos ni estadounidenses, que son los que nos dotan con una capacidad cognitiva y una potencia creativa incomparables, inalcanzables (aquí emerge el Eurocentrismo²).

La anterior afirmación coincide con la percepción del geógrafo James M. Blaut en cuanto al fervor con que desde los tiempos de la Ilustración se ha implantado en nuestra tradición cultural una oscura y eficiente semilla para negar la unidad psíquica de la humanidad (Koepping, 1983): afirmar la división entre las sociedades y las culturas que son más creativas, inventivas e inteligentes (razón por la que acumulan más riqueza y prosperidad) y el resto del mundo (condenados a la escasez por su incompetencia).

Esta tensión por la supremacía en la producción de conocimiento es el hilo que genera el suspense narrativo en el filme de Greengrass, reflejado en la lucha de "inteligencias" que se establece entre el capitán (interpretado por el actor Tom Hanks) y Muse, el líder de los secuestradores (interpretado por Barkhad Abdi). Uno discurre su peripecia concentrado en averiguar el mejor modo de liberar a su tripulación y después a sí mismo, mientras que el otro se aferra desesperado a la posibilidad de ganar un rescate (enamorado del sueño de hacerse rico, de poseer el acceso a un área del mundo que le ha sido vetado desde su nacimiento). Pero en el curso del relato, la inteligencia individual del capitán Phillips termina por ser sustituida por la Inteligencia de toda su nación. La estructura militar, boyante de innovación tecnológica, absorbe la responsabilidad de difundir el modo ordenado de concebir el mundo, expresado de forma aparente en la garantía de seguridad plena para el movimiento y la integridad de cada uno de sus ciudadanos, sea cual sea su condición social (activada la superestructura ideológica) y, aplicando un mayor alcance al análisis, en garantizar la seguridad de movimiento de los capitales (permitiendo la protección de la subestructura económica) (Jameson, 1989). El siguiente paso es conectar la concepción del difusionismo con el modo de colonizar el mundo que concibió Occidente desde el Renacimiento, y que pervive en nuestros días a pesar de la evolución geopolítica y económica de algunas áreas "Outside" del mundo.

La carrera por cristalizar un sistema de ideas que concibe la historia como una secuencia en movimiento, que progresa sin cese, adquiere fuerza a partir del siglo XVI, acompañada por la emergencia paulatina del capitalismo moderno, cuya expansión va distribuyendo más oportunidades de prosperar a sectores de la población europea que habían estado excluidos por las rí-

\footnotetext{
2 La aproximación al concepto de Eurocentrismo para esta investigación es directamente crítica y desambigua, negando la superioridad europea que postula la tradición de las instituciones en una multitud de aspectos civilizatorios, dado que estas han sido proclives a mezclar prejuicios, mitos y opiniones superficiales con hechos empíricos bastante más complejos de refutar al haber adquirido el rango de verdades científicas legitimadas por los esfuerzos de la élite intelectual de la época (¿Los europeos han sido los únicos inventores del capitalismo, la ciencia, la industria o la democracia?). Hoy en día, lo más extendido es que cualquier científico europeo rechace la noción de Eurocentrismo de igual manera que se han estigmatizado otras actitudes y creencias como el machismo, la eugenesia y la superioridad racial. Sin embargo, esta situación no implica que se haya dejado de creer en las consecuencias de algunas de las ideas contenidas en el paradigma del Eurocentrismo. Quizás, la diferencia estriba en que cuando ahora alguien con criterio defiende algunos de los presupuestos que le eran connaturales al paradigma, lo hace porque cree que se está refiriendo a hechos científicos válidos que han sido demostrados suficientemente, y siempre alejados de supersticiones o fórmulas políticas o religiosas subjetivas y utilitaristas.
} 
gidas normas medievales. El esfuerzo ideológico de los que buscaban reformar definitivamente la herencia del medievo colocó el acento en convencer a las estructuras más conservadoras de la sociedad de que el progreso era un fenómeno natural, inevitable y benigno. Por supuesto, este arranque se asoció con la religión para dinamizar la capacidad de admitir las nuevas ideas entre las clases que podían sentirse más amenazadas por ellas. Luego la capacidad innovadora de los países derivaba directamente de la fe cristiana, por tanto y en última instancia, sus productos eran frutos de Dios. En paralelo, la experiencia del Nuevo Mundo se utilizó para articular la visión de los que "están fuera". La conquista de sociedades menos desarrolladas tecnológicamente y carentes de un sistema racional de pensamiento equivalente al del conquistador permitió armar la mitología de la justificación: la inferioridad de las razas y pueblos conquistados autoriza por ley natural a que todos los nativos provean con trabajo, tierra y productos a los europeos; a cambio, éstos supuestamente modernizan la zona explotada, trayendo la civilización superior. Entre los siglos XVII y XIX, se termina de cerrar todo el sistema de creencias acerca de los nativos del "Outside", y se hace un esfuerzo por aprender de ellos todo lo posible (su lengua, sus costumbres, sus religiones, su modelos de organización social y política), pero el objeto final no es el conocimiento por el conocimiento, sino teorizar sobre el bien común que supone colonizar aquellas tierras y convertirlas en negocios extraordinariamente beneficiosos para el progreso del "Inside". Sin lugar a dudas, la esclavitud y la expropiación de tierras y recursos naturales son los factores económicos fundamentales sobre los que fueron creciendo diversas concepciones filosóficas y descubrimientos científicos que contribuyeron directa o indirectamente a su perpetuación, convirtiendo todas las formas de explotación en asuntos legales y sanos. Una de las teorizaciones más celebres y decisivas fue que los no-europeos carecían de un sistema de propiedad privada mínimamente desarrollado, y por ello nunca habían sabido sacar rendimiento económico y comer- cial del uso y cultivo de la tierra (Chandra, 2012). Este supuesto primer gran "vacío" fue aprovechado para impulsar la creación de numerosas corporaciones colonialistas para administrar la propiedad de la tierra y la extracción de los recursos de los pueblos colonizados. El segundo "vacío" que se utilizó para justificar la explotación fue la baja densidad de población de muchas áreas (difundiendo la idea de que la inmensa mayoría de los pueblos nativos eran nómadas, sin unidad política y, por ello, incapacitados para reclamar la soberanía de sus territorios). Finalmente, el tercer elemento que curaba de posibles contradicciones a las dos proposiciones anteriores fue el denominado "despotismo Oriental" (Hall, 1989), cuyo argumento fue tildar de salvajes las normas de conducta de ciertas sociedades más estructuradas, acusándolas de no tener asimilada la idea de libertad y justicia según el canon occidental y cristiano. Tal atraso producía que sus formas de gobierno estuvieran negando cualquier posibilidad de progreso. Una vez más, debían ser los europeos quienes trajeran la idea de libertad en la forma de su modelo de colonización. En suma, todas estas concepciones armaron la creencia en la superioridad del Eurocentrismo, sirviendo para legitimar el sistema de ocupación que implicaba.

Una vez llegado el siglo XX, la evolución del difusionismo, especialmente tras la Segunda Guerra Mundial, encontró una nueva complementariedad para dejar latente la idea de la neocolonización: la construcción del mito de “Tercer Mundo". Una simbología explícita por la que hemos aprendido que ciertas partes del globo tienen como característica intrínseca no ya unas dosis elevadas de pobreza y desigualdad social, sino la falta de modernización fruto de la nulidad de sus poblaciones para alcanzar las claves sociales y económicas para un buen funcionamiento (prejuicios para estigmatizar a todos sus miembros como seres indisciplinados y de bajo carácter) pese a tener reconocida la soberanía de sus diferentes territorios (carencias cuya causa principal sigue siendo de clave internista y ahistórica). 
La "nueva piel" del difusionismo contemporáneo flota suspendido en la concepción que Peter Greengrass transmite en el filme sobre las causas materiales más directas que favorecen la aparición de la piratería en Somalia (un país dominado por clanes paramilitarizados que esclavizan a tribus y poblados, y cuyo funcionamiento productivo e institucional es todavía "antiguo", "salvaje" y "atrasado", como consecuencia de carecer de un sistema democrático robusto y de un marco legal en el que el capitalismo pueda "creer" o tener confianza). El difusionismo que se sigue desarrollando en el siglo XXI fundamenta su tesis prácticamente como lo hizo hace 150 años: la modernización es el motor que hará entrar a los países del "Tercer Mundo" en la historia, y dicha modernización solo será posible mediante políticas públicas que implanten la forma administrativa, productiva y cultural de la metrópoli europea, en cooperación con la implantación de empresas privadas patrocinadas de nuevo por la metrópoli para acelerar el crecimiento económico de la zona. Por consiguiente, aquellos países del Tercer Mundo que han mejorado su situación en los últimos 50 años lo han hecho gracias a creer en ese modelo de gestión que a su vez, desde el corazón de la doctrina difusionista, supone un juego de ganar-ganar para ambas partes (una elección racional). Rechazar la modernización en los términos eurocéntricos, es decir, en los parámetros del expansionismo capitalista, es una elección irracional que genera el caos social y político, ampara el crimen y la extorsión y, en último lugar, perpetúa la hambruna.

Una primera conclusión para poder interpretar el contexto socio-histórico que recrea la película es el reconocimiento que hace su propuesta narrativa de que EEUU y de refilón Gran Bretaña, en representación de Occidente, son los centros permanentes de innovación e invención de la humanidad desde que se inició la modernidad. Ambas naciones son los motores del comercio global, y también son los protectores de un modo de interpretar el mundo, el capitalista, insuflándolo de orden y sosiego para administrar los ciclos económicos y establecer la división del trabajo. Precisamente, en el tercer acto del filme, se describe muy bien la mentalidad de la especialización en la profesión militar cuando el comandante de la fragata pierde el mando sobre la operación de rescate de Phillips, tras fracasar con su estrategia de negociación, siendo remplazado por un equipo de fuerzas especiales Navy SEALS. En la lógica pretendidamente racionalista del capitalismo siempre tiene que haber preparada una pieza más eficiente para poder resolver el problema no imaginado por el resto. Tal ejercicio es la base del pensamiento creativo en su modelo de producción económico, en el sentido de que la imaginación es una herramienta para generar invenciones que sirven para mantener el statu quo, para anticiparse al conflicto, al riesgo y, en nuestro ejemplo, a la insurgencia y al terrorismo.

La segunda conclusión, como efecto de la anterior premisa, es la producción de otro reconocimiento hegemónico adicional: el elitismo espacial que fija un centro e identifica una periferia externa, distribuyendo como un conocimiento de tipo racional (a mi juicio pseudocientífico) que el modelo "Dentro-Fuera" ("Inside-Outsi$d e$ ") es una forma válida de entender el movimiento de la Historia. La consecuencia final de estas creencias es continuar negando la unidad psíquica del hombre ${ }^{3}$, y así poder seguir explicando que las razones por las que una nación fracasa mientras que otra triunfa, vienen determinadas por la calidad democrática de sus instituciones, y por la inteligencia y el carácter predominante de los miembros de su sociedad, desligando el destino histórico y el cambio social del modelo de producción económica dominante con sus respectivas leyes de funcionamiento, así como despreciando la influencia del inconsciente en la consciencia colectiva y la mentalidad histórica. 


\section{EL INCONSCIENTE POLÍTICO: TRABAJO Y REPRESENTACIÓN IDEOLÓGICA DEL TERCER MUNDO}

Antes de continuar, resulta conveniente recordar que estamos en el terreno metodológico del metacomentario. Por lo tanto, se trata de un acto interpretativo de tradición marxista que permite al receptor, con toda la densidad y la esencia transhistórica del pensamiento dialéctico, apropiarse de la obra para recombinarla como una construcción alegórica ${ }^{4}$ y política, y de este modo revelar los significados ocultos así como desentrañar las causas originales.

Para llegar a una tercera conclusión que complete las expuestas en el epígrafe anterior, y aplicando la noción del inconsciente político desarrollada por Fredric Jameson, se necesita observar cómo los procesos económicos influyen en los procesos psíquicos de los individuos a la hora de que estos articulen sus relaciones sociales, generalmente basadas en una fantasía política que sirve de justificación a las contradicciones de la vida real. Precisamente, al comienzo del filme, el autor nos presenta la vida personal de Richard Phillips en Estados Unidos, casado y con varios hijos. En este segmento de breves escenas observamos cómo es su vivienda y su vehículo, las propiedades arquetípicas de la "clase media” occidental. Muestra también cómo su mujer, una profesional con empleo, le lleva al aeropuerto para que viaje a su nuevo destino, a más de $10.000 \mathrm{~km}$, donde se hará cargo del carguero "Alabama". En la secuencia del trayecto en coche, con un paisaje típicamente urbano y postindustrial, se produce una conversación del matrimonio: Phillips se queja amargamente, tiene que separarse de su familia para ir a ganarse la vida al otro lado del mundo, y esta realidad le hace reflexionar sobre "lo duro y difícil que lo tendrán sus hijos" para encontrar un empleo digno y poder formar una familia como la suya. El matiz de esta preocupación se desliza hacia otro campo de acción política que conecta la inseguridad de acceder al mundo del trabajo con la inseguridad que provoca una realidad exterior que cada día se vuelve más hostil. Por ende, la preocupación que se traslada al espectador es que el mundo ha cambiado para hacerse menos seguro ${ }^{5}$, generando menos confianza y optimismo para una época de paz y justicia asociada a la complejidad socio-histórica que nos rodea. El estado mental de alerta y angustia queda planteado tanto para la evolución emocional de los personajes como para la audiencia. De vuelta a la diégesis, es la esposa de Phillips quien cierra el diálogo de un modo sincronizado culturalmente con la vieja tradición del eurocentrismo -sobreponiéndose al desánimo, aprueba que esa es la manera de funcionamiento de la naturaleza-, sirviendo terapéuticamente como un mecanismo de disten-

3 La noción de unidad psíquica de la humanidad hay que entenderla en la línea de Adolf Bastian y de Carl Jung. Así, de acuerdo con los trabajos de Bastian, comparto la idea de que todos los seres humanos tienen en común una estructura mental básica. De modo que los actos mentales de las personas en todas las partes del planeta son producto de los mismos mecanismos fisiológicos característicos de la especie humana; lo que hoy en día podríamos llamar la carga genética sobre la organización y el funcionamiento del sistema neuroendocrino. Cada mente humana hereda un complemento de las ideas elementales $\mathrm{y}$, por lo tanto, la mente de todas las personas, independientemente de su raza o cultura, funciona en términos generales de la misma manera. El objeto de la investigación de Bastian no fue el estudio del individuo como un agente cerrado, sino el estudio de las ideas populares -culturaleso la "mente colectiva" de un pueblo en particular. Si el individuo es un animal social cuya mente (sus ideas populares) está influenciada por su entorno social y geográfico, las ideas elementales son la base sobre la que las ideas populares se desarrollan. Desde esta perspectiva, el grupo social tiene un tipo de mente de grupo, una especie de "alma" social, en el que se incluye la mente individual. Se debe yuxtaponer a la perspectiva de Bastian (quien consideró que las teorías de Darwin eran excesivamente especulativas) el marco antropológico evolutivo desarrollado por Gregory Bateson (bosquejado en el punto anterior sobre la cartografía cognitiva) para entender de un modo más completo la manera en la que la cultura opera y modifica nuestra visión psicológica del mundo en el largo plazo. Véase Gregory Bateson. Pasos hacia una ecología de la mente (1998).

4 En relación al concepto de alegoría, al aludir a él estoy describiendo el resultado de un método de reescritura tanto de una obra de arte concebida para la reflexión, como de una obra cultural concebida para un consumo instantáneo y superficial. El enfoque de la alegoría es una pértiga para saltar las formas tradicionales de interpretación (fórmulas ideológicas dominantes) con las que habitualmente realizamos la descodificación de una obra dada, de modo que puedo esforzarme por atrapar la realidad que se esconde tras la apariencia (falsa) de las cosas.

5 Tanto en la novela que sirve de referencia para la película como en los medios utilizados para su promoción, se citó que el suceso real representó el primer secuestro de una nave de carga estadounidense en 200 años. Véase: http://www.imdb.com/title/ tt1535109/ 
sión -la idealidad de la estructura familiar- para restablecer la lógica racional capitalista. ${ }^{5}$

Esta introducción se enfrenta con el entorno en el que vive Muse, a la postre, el líder de los secuestradores: nacido en un pequeño pueblo de pescadores somalí6, profundamente pobre y retrasado tecnológicamente, donde sigue existiendo una organización patriarcal con reminiscencias feudales ${ }^{7}$ representadas por el modo de estructurar la división del trabajo y repartir los medios de subsistencia, así como por la manera de ejercer y heredar el poder. La coerción que practican los "grandes señores" paramilitarizados para que los jefes de estas pequeñas tribus accedan a convertirse en mercenarios a su servicio se presenta de un modo premeditadamente sincopado mediante una ráfaga de planos muy rápidos. La puesta en escena del director termina por provocar un mensaje muy grato de entender para el espectador europeo, plenamente acostumbrado a leer este tipo de cine político: dado que los miembros de estas poblaciones sufren una gran privación para vivir dignamente, en cierto modo se ven empujados a utilizar medios ilegales para poder sobrevivir, teniendo a menudo que hacer uso de la violencia. Y, por otro lado, como se mencionó anteriormente, la ausencia de un sistema democrático, cuya pureza como medio de organización está reservado para la cuna civilizatoria localizada en Europa, que sea capaz de gestionar eficientemente la economía queda diagnosticada como una de las principales causas ${ }^{8}$ para que afloren hábitos de explotación practicados por los más fuertes (gente armada) sobre los débiles. De hecho, ante el espectador, se recrea un proceso social por el que la piratería se transforma en un trabajo remunerado para los jóvenes pescadores somalíes, captado en la escena en la que Muse recluta voluntarios para que le acompañen en la misión que le ha sido encomendada; una alegoría alrededor de los denominados trabajos "informales", una característica común en el Tercer Mundo.

Durante décadas, los teóricos de la moderni- zación, formados en las bases programáticas de la Alianza para el Progreso ${ }^{9}$, defendieron que el sector informal -empresarios y trabajadores carentes de una regulación sobre derechos y obligaciones laborales, avocados a una opresión extralegal- que proliferaba a ritmos agigantados en los países en vías de desarrollo debía ser un trampolín de gran utilidad para que los trabajadores del campo aprendieran un oficio con valor y poder ser absorbidos después por el sector formal de las grandes ciudades que, principalmente desde la década de 1970, comenzaron lentamente a industrializarse y atraer a una superpoblación, ya fuera en África, India o resto de Asia. Sin embargo, los estudios de especialistas de la Organización Internacional del Trabajo (Oberai, 2003) han venido demostrando cómo este sector informal (bajo cuyo paraguas quedan más

6 De acuerdo al MPI (Multidimensional Poverty Index), elaborado cada año por el Programa de las Naciones Unidas para el Desarrollo, Somalia es el $6^{\circ}$ país más pobre del mundo (superado únicamente por Níger, Etiopía, Malí, Burkina Faso y Burundi). Ver: Informe sobre Desarrollo Humano 2014. PNUD (2014).

7 La persistencia de formas de producción precapitalistas en estos países suele ser una consecuencia del modo de producción colonial. Este modo de producción colonial generalmente no fue ni estrictamente feudal ni estrictamente capitalista sino que dio lugar a su propia dinámica de relaciones sociales. La consecuencia histórica tras el proceso formal de descolonización es la evolución del modelo social colonial a otro modelo que en muchos casos todavía no es capitalista, sino que ha podido recuperar algunos elementos típicamente feudales. Véase Hamza Alavi. Capitalism and Colonial Production: Essays on the Rise of Capitalism in Asia (1982).

8 Para contrastar esta creencia ideológica es conveniente estudiar los movimientos nacionalistas de independencia del siglo XX sobre el modelo colonial europeo. Uno de los principales esfuerzos intelectuales y de comunicación política de estos movimientos siempre pasó por demostrar como falsa la premisa imperialista de que la debilidad de la economía local se agravaría enorrmemente si abandonaban la responsabilidad colonialista y concedían la independencia absoluta. Véase Bipan Chanda. Rise and Growth of Economics Nationalism in India (1966).

9 La Alianza para el Progreso (Alliance for Progress) fue un programa de ayuda económica, política y social de EEUU para América Latina efectuado entre 1961 y 1970. Aunque se proyectó una inversión de 20.000 millones de dólares, lo cierto es que su valor práctico quedó en entredicho al no producirse la elaboración de planes viables ni las reformas económico-sociales que exigía la concesión como contraprestación de la ayuda. Otro factor para su cierre fue la dirección de la política exterior estadounidense, que abusó del intervencionismo en algunos Estados como prerrogativa para conceder las líneas de crédito. 
de 1.000 millones de personas en el mundo en nuestros días) se ha sedimentado como una bolsa permanente de subempleo y desempleo enmascarado, en el que la movilidad social que se preveía, en la práctica es prácticamente nula. Así por el contrario, lo que ha germinado en estas zonas del mundo como resultado es la estructuración de una burguesía informal que se vale de un proletariado informal (Davis, 2001: 230 y ss.). Este desarrollo histórico desemboca en la producción de formas desiguales de trabajo asalariado al servicio de un sector no regulado que, en mayor o menor medida, trabaja en la más absoluta clandestinidad. Esta situación vital conlleva una presión psíquica y cultural de tal magnitud que cuando el asalariado clandestino, de un día para otro y transitoriamente, pasa a convertirse materialmente en un empresario clandestino (se trata de proceso muy generalizado), reproduce la misma forma de explotación que él mismo ha sufrido (Breman, 2003).

Profundizando en los mecanismos que relacionan el inconsciente colectivo con la conciencia social dominante y su negación, y partiendo de categorías jungianas, la subjetividad (al estar formada por la conciencia social y por los arquetipos que definen nuestro inconsciente colectivo) desactiva eficazmente la ingenua idea alrededor de la soberanía de nuestro Yo, como si éste fuera un ente que obedece únicamente a nuestra voluntad individual (Jung, 2012: 258 y ss.). Para prosperar en el mundo del eurocentrismo, la cultura dominante que fluye sobre la subestructura económica programa, a través del aprendizaje formal, que nuestra conciencia debe buscar significado y dirección en las representaciones y opiniones que subyacen en la conciencia social colectiva. Mientras tanto, y respetando la exigente premisa de racionalidad, el inconsciente debe permanecer reprimido por su naturaleza irracional. Sin embargo, a medida que el inconsciente colectivo es reprimido con afán, la actitud represiva que es ajustada para tal ejecución termina por adquirir un carácter fanático in crescendo que modifica al Yo, habilitándose el proceso de enantiodromía ${ }^{10}$. De este aparataje se filtran dos desarrollos posibles:

(I) La autonomía del Yo queda coartada por las tendencias imperantes en la conciencia colectiva (hombre-masa). Así, tanto el líder político como el líder religioso buscan que el sujeto acepte una determinada verdad unilateral, logrando anclar una creencia innegable en su conducta y, por consiguiente, en su interpretación psicológica del mundo: la oposición dual y radicalizada entre optar por el Bien o por el Mal.

(II) El individuo tiende a captar convicciones, en vez de adquirir conocimientos cuya complejidad pueden colocarlo frente a un espejo de contradicciones permanentes. Por ende, el Yo opta por la opción más cómoda de imitar pero adquiriendo como contraprestación una falsa sensación de equilibrio. En realidad, su predisposición se dirige hacia la destrucción, tanto del equilibrio en la sociedad como en su mundo íntimo. Su incapacidad para encontrar una estabilidad psíquica entre opuestos se manifiesta en que no integra elementos del inconsciente en su consciencia.

Si se aplican ambos desarrollos a la representación de los personajes principales de la película se puede observar lo siguiente:

(I) Muse genera un duelo por el poder frente al arquetipo del padre (que en su representación consciente se trifurca en la tensión que establece con su padre biológico, que ostenta el poder en el poblado y que aquel busca heredar, con el padre "blanco" que representa el capitán Phillips, y con el Gran Padre al que representan las fuerzas del ejercito de EEUU). Pero esta representación múltiple es en sí un rasgo más característico de los autores del filme que de una interpretación verosímil de la base antropológica presente en el carácter y la tradición somalí. Aplicando el enfoque de la mentalidad del hombre primitivo (Lévy-Bruhl, 2003: 97 y ss.), lo extendido sería que el individuo somalí pensara en todo momento en los

10 La enantiodromía es un proceso de conversión en lo opuesto. Por ejemplo, el individuo cuyo dominante ha pasado por ser pacífico se torna violento, o aquel caracterizado por su optimismo adquiere el impulso al suicidio. 
términos de su grupo familiar o tribu. Esto quiere decir que el bien de la tribu ocuparía su primer objetivo psíquico. Otra particularidad sumamente importante para este tipo de mentalidad es el empleo de la primera persona para explicar la historia o el presente material de las cosas (de modo que lo experimentado por sus antepasados, así como los logros de la comunidad en el presente se fusionan como parte del Yo). Además, hay que tener en cuenta que la propiedad de la tierra no se concebía como un bien de uso privativo individual, ni tampoco estaba basada en el disfrute de un derecho para su posterior venta.

(II) El choque interpretativo de la visión ilustrada con ambición civilizatoria tiende a dar la máxima importancia a la opinión individual y al líder que la impone. Por el contrario, una constante en numerosos estudios realizados desde finales del siglo XIX a principios del siglo $X X$ sobre la diversidad cultural $y$ religiosa de tribus y etnias en África, constataron que la opinión colectiva era la que más valor poseía en cualquier grupo social, y que lo más habitual era que todos los miembros de una misma tribu compartieran una psicología social milimétricamente igualada y estable en cuanto a su reacción ante los mismos estímulos ("Las cosas no se hacen en nombre de ningún yo, sino en nombre de un nosotros" Monteil, 1924: 220).

Consecuentemente, el prisma eurocéntrico diluye todos los mecanismos de socialización tendentes al colectivismo, sustituyéndolos por el complejo de individualización para, desde ese marco referencial, enmascarar la participación de la psique de cada persona en los resortes y experiencias de una vida común acumulada históricamente, favoreciendo el enardecimiento de la fantasía individual. En contraposición, los rituales y los procesos educativos del hombre "primitivo" (es decir, los que se sitúan fuera del canon eurocéntrico) se focalizan en desarrollar el potencial de cada individuo, que será siempre acorde con las cualidades paralelas del resto de individuos de la comunidad. En orden a este razonamiento, el personaje de Muse se construye como un insurgente a su propia tradición, ya que se rebela contra el conformismo obligatorio de asemejarse a los otros integrantes de la tribu. Su aspiración a lo largo del filme, netamente occidentalizada, evoluciona como un reto para alterar el equilibrio, consistente, primero, en subordinar a los deseos de su propia voluntad los intereses del grupo que le acompaña en el secuestro y, segundo, en materializar el contagio que ha sufrido del mítico sueño capitalista del beneficio como placer supremo (por ende, transformarse por cualquier medio en un hombre autentico para el orden del capitalismo).

En cuanto al proceso psíquico del personaje de Richard Phillips, se genera una tensión con el arquetipo jungiano de la sombra, emanando una lucha interna por controlar sus impulsos más primitivos (pánico-ira) a la hora de relacionarse con sus secuestradores, con Muse, y con las posibilidades de supervivencia que va calculando en el desarrollo de su peripecia. El arco emocional de Phillips a lo largo de la narración se mueve entre la opción por actuar de un modo racional y empático (por consiguiente, hacer valer una inteligencia moral superior, dada culturalmente), y la opción de dejar emerger a la conciencia sus instintos moralmente más desechables e inferiores. Destaca la secuencia que cierra la película en la que se muestra la catarsis definitiva de Phillips.

En ella lo observamos en estado de shock mientras es atendido por una médica militar que comprueba si ha resultado herido tras el tiroteo final. Si su desmoronamiento psíquico viene dado por la fuerte dialéctica entre los opuestos que se han movido desde su inconsciente colectivo hasta su conciencia, lo cierto es que resulta imposible validarlo dado que es un personaje de ficción, pero la alegoría política que interpreto en base a las categorías narrativas explicitadas por el autor del filme, es la de un hombre corriente, un trabajador asalariado que ha soportado una situación extraordinaria para la que no tenía un entrenamiento especializado, y cuyos efectos obviamente no es capaz de asimilar del mismo modo, frío y automatizado, con el que lo hacen los profesionales militares. Pero el alcance mayor de la reescritura recae sobre el perfil del trabajador occidental, forzado a desplegar su 
fuerza de trabajo a escala mundial, compitiendo por un precio que difiere según la zona del mundo, y que discurre vitalmente desprovisto de una hoja de ruta para alcanzar un sentido humano de felicidad: la vuelta al hogar ya no es tan clara ni resplandeciente como antaño (las secuencias del inicio en su residencia en EEUU están fotografiadas con tonos grises y plomizos, el paisaje mostrado carece de vida social salvo para la producción económica, y los sentimientos expresados en los diálogos y gestos de los protagonistas rezuman pesimismo e inseguridad).

La guinda a la representación ideológica del Tercer Mundo que reconstruye el filme viene en la forma de una re-conceptualización del espacio geográfico mundial basada en su vigilancia (militar) y a una estructuración cognitiva asociada al darwinismo social. Comienzo este desarrollo partiendo del geógrafo crítico Mike Davis quien, en sus estudios sobre la ecología urbana de mega-ciudades como Los Ángeles (Davis, 1992 y 2001), descifra cómo en las democracias contemporáneas más avanzadas se produce la implantación de apartheid espaciales (que proyectan urbanísticamente la combinación de media luna y diana ${ }^{11}$ descrita por Ernest W. Burgess, para estructurar la lucha de clases según el modo en el que se distribuye cada una de ellas en barrios y tipos de vivienda), en cuya composición se mezclan factores como la renta del trabajador, el valor del suelo, la raza, la religión y lo que Davis considera como un elemento diferencial con otras épocas de la historia: la gestión del miedo. El resultado, en términos generales, se desliza hacia la interiorización de una creencia que termina por hacerse realidad, esto es, la vida social de la comunidad se percibe como algo permanentemente amenazado por todo lo que es exterior a ella. La consiguiente reacción consiste en aceptar la irrupción de múltiples estrategias de seguridad policial, junto a la integración natural de soluciones tecnológicas que anestesien la sensación inducida de pánico.

De un modo similar, Jameson, al consignar su noción de cartografía cognitiva con la experiencia cultural resultante de conectar nuestra percepción psicológica del espacio con la actividad social y el valor político que se desarrolla dentro de ese espacio (y que se le otorga institucionalmente), pone en evidencia el mapeo cognitivo que practicamos a través de las formas culturales con las que son representados países del África Oriental (Sudán, Etiopía, Somalia, Kenia, Tanzania), con el común denominador de identificarse como zonas económicamente pobres (atrasadas técnicamente e inestables socialmente), lo que condiciona el modo en el que es programada nuestra visión política sobre la realidad local mostrada, afectando, en última instancia, a la interpretación histórica que aceptamos como válida culturalmente. Las consecuencias a largo plazo de todo este complejo ideológico se sintetizan en creer en una determinada ecología humana, justo aquella en la que nuestro devenir individual, nuestra aventura casual, absorbe como valores de significación para lo cotidiano todas aquellas características básicas con las que funciona políticamente el planeta en su conjunto (Sistema-mundo).

\section{ESPACIO Y LIBRE COMERCIO PARA EL CAPITAL: LA HEGEMONÍA DEL IMPERIO}

Tal y como apuntó Marx, no es posible deshacerse del trabazón entre el modo en el que se producen las ideas y cómo se instalan las representaciones del mundo en la consciencia, y cómo es realmente la actividad material, el funcionamiento de las relaciones comerciales y el propio lenguaje que los hombres emplean entre sí para intercambiar esas mismas ideas junto al producto de su trabajo, de manera que el pensamiento aparece como "una emanación directa de su comportamiento material”(Marx-Engels, 2014: 21). De acuerdo a esta tesis, sería cierta la

11 La denominada combinación de "media luna y diana" desarrollada por Ernest W. Burgess disecciona la distribución espacial de las clases sociales en el plano urbano, analizándola como una interacción evolutiva de ecos darwinianos compuesta por fuerzas de invasión, competencia, descendencia y simbiosis. Ver: Robert E. Park, Ernest W. Burgess. The City: Suggestions for Investigation of Human Behavior in the Urban Environment (1984). 
imposibilidad de que la consciencia sea autónoma con respecto al modo en el que está estructurada la vida real y la subestructura económica de reproducción.

La conexión entre esta concepción materialista (la imposibilidad de que la consciencia sea autónoma con respecto al modo en el que está estructurada la vida real y la subestructura económica de reproducción) y la diégesis se fundamenta en que los acontecimientos históricos recreados no pueden dejar de ser una interpretación ideológica relacionada con el desarrollo del comercio y con las relaciones industriales que han ido expandiéndose globalmente. En la narración queda objetivada la ruta comercial por la que cientos de miles de naves de carga, operando desde los puertos de Oriente Medio y Asia del Sur (periferia), transportan mercancías producidas en los países de esas zonas geográficas hacia los países occidentales (centro). Este movimiento espacial de mercancías, como fenómeno histórico, queda contrastado por la falta de desarrollo material de los países de la costa oriental africana, marginados del modelo de producción global al estar basado en la asimetría en el valor (precio) de la fuerza de trabajo. Ante esta situación, parece preciso rechazar la hipótesis de que los mecanismos inherentes a la mundialización del capitalismo tienen como efecto la homogenización de las condiciones económicas en el mundo. Es su contrario: la eficacia de su rendimiento pasa por profundizar en la radicalización de las diferencias de riqueza entre el centro del "imperio" y el dominio de sus "límites exteriores". La violencia social y económica que desencadena la lógica de este modelo expansivo se convierte en uno de los factores principales que provoca que la lucha de clases en los países pobres sea sublimada a través de la ira, implantada culturalmente sobre los símbolos de poder de los países ricos, lo que es otra forma de encauzar la marginalización derivada de la ley de la pauperización, necesariamente presente para cumplir con la acumulación del capital (Amin, 2011: 94).

En un diálogo de Muse con Phillips, el autor deja escapar una crítica políticamente co- rrecta sobre los motivos por los que se produce la conversión de la renta del pescador en una renta devaluada por el funcionamiento del comercio exterior (cuya fuerza de trabajo, en este caso, son las flotas pesqueras de los países occidentales) que extrae los recursos del mar sin un criterio ecológico y sin integrar las necesidades comerciales de las economías locales (incapacitadas para ser competitivas dado su retraso técnico y la inestabilidad política que les rodea). En este punto, lo que subyace es la ideología de los costes ecológicos absorbidos por la lógica de la cultura del consenso (entendida ésta como el "capitalismo sostenible"). Se llega así a la nueva doctrina de los derechos de acceso a los recursos del planeta, que no es más que la mercantilización para licitar los recursos mundiales para que las empresas transnacionales y resto de oligopolios, admitiendo una carga impositiva de compensación para el país de origen, adquieran la protección legal para desplegar todas sus capacidades tecnológicas y de inversión para sacar ventaja de ellos, quedando patente el cordón umbilical entre la "infraestructura espacial" y la "acumulación por desposesión”. Precisamente, el núcleo de la tensión narrativa del filme se centrifuga en cómo funcionan los resortes para proteger, bajo el marco legal internacional de naturaleza eurocéntrica, la actividad comercial de los oligopolios, conectados a los sistemas de seguridad global bajo la tutela británica y estadounidense a través de sus fuerzas militares navales.

La diferenciación política trascendental recae en que el discurso interpretativo materialista no coincide con la visión ecológica del consenso (entendida esta como un retorno mítico de la consciencia del hombre a un estado espiritual basado en el contacto con la naturaleza, y su educación en un consumo sostenible acorde con el espacio absoluto) ni con la crítica socialdemócrata sobre las teorías del crecimiento económico que provocan la desigualad de renta. En contraposición, la tesis de Marx era mucho más concreta, más real, al relacionar el fin de la racionalidad del capitalismo con la búsqueda del beneficio inmediato, una ley de funcionamiento 
que negaba cualquier propósito de sustituir el fin sin transformar todo el modelo. Las consecuencias del discurso ecologista encapsulado dentro del capitalismo cultural convergen en la creación de las condiciones necesarias para que la sociedad desconfie de sus propias posibilidades de perfeccionamiento social. Así, permitiendo que la superestructura continúe operando sin cambios, queda instalada la creencia en que el producto de la ciencia y la evolución de la conciencia humana serán incapaces de frenar la inercia que lleva al agotamiento de la biocapacidad de nuestro planeta (Wackernagel-Rees, 2009: 2728). Luego, como la escasez será inevitable y el egoísmo seguirá predominando, los planteamientos neomaltusianos cobran utilidad para transmitir la alarma política con la que justificar una nueva expansión del imperio, mediante el despliegue de sus fuerzas productivas para asegurarse los recursos para su propia supervivencia (Harvey, 2007: 75-80). La metáfora política que hubiera podido correlacionar la recreación narrativa con la coherencia de un enfoque materialista radical hubiera sido aquella en la que, dentro del adecuado tratamiento del contexto socio-histórico, los actos de piratería hubieran designado una posición confiscatoria de los países del Sur como acto de resistencia frente a la renta derivada de la expansión imperialista a través del comercio mundial. Es decir, que la piratería se hubiera retratado como una expresión de rechazo a la renta residual que distribuye la globalización (basada en la jerarquización de los precios de la mano de obra y del precio de acceso a los recursos naturales). Sin embargo, lo que ocurre en la narración es el proceso cultural inverso, ya que todo el significado del secuestro queda finalmente devaluado a un acto de egoísmo vulgar, como lo prueba que Muse solo acceda a negociar la liberación de Phillips en el último momento, cuando su demanda psicológica (la codicia) queda cubierta por la astucia (metis) que aplica el héroe enviado por el "imperio" estadounidense (el líder del equipo de los Navy SEALS). Mediante tal caracterización psicológica del "terrorista", la posibilidad de elucidar un dis- curso crítico queda inaccesible para el consciente del espectador. A cambio, todos los elementos de la milimétrica puesta en escena en el clímax final inducen a sentir placer por la superioridad ética de los valores eurocéntricos, y por el espectáculo que ofrece el desarrollo tecnológico de la fuerza militar desplegada, reproduciendo la validez de la idea que permite que el pueblo de los Estados Unidos incapacite a los secuestradores sin remordimientos ni restricciones legales (eliminándolos drásticamente, sin dejar rastro de preocupación ni temor ante cualquier amenaza para el dominio que ejerce su modelo social, político y económico).

\section{LA APARIENCIA DE NEUTRALIDAD COMO LA "NUEVA" PSICOLOGÍA DEL ESTILO CINEMATOGRÁFICO}

El tipo de cine al que se adscribe Capitán Phillips queda en los confines del naturalismo artístico (para el caso de una clasificación más específica se ubicaría en el realismo general cinematográfico). Esta adscripción implica afirmar dos principios: (I) El naturalismo debe quedar siempre diferenciado del concepto de imitación. Más aún, para tener el aura de arte, el naturalismo debe distinguirse afiladamente de la pura mimesis del modelo existente en la naturaleza. (II) Debe producirse una aproximación estética a la verdad material y orgánica de la vida, pero el objetivo no puede quedar causado porque el artista pretenda lograr la ilusión de que su recreación sea tan verosímil que nos parezca que el objeto reproducido adquiere vida propia ante nuestra cognición, sino por el sentimiento de belleza que logra expresar inspirado por la vida del objeto orgánico; ahí reside el sentimiento que busca satisfacer el creador, es decir, cubrir la demanda que motiva su propia volición artística ${ }^{12}$.

12 La evolución del arte se concibe como una evolución de la
volición, pero asumiendo que esta viene determinada tanto por el
desarrollo psíquico del artista como por una compleja interacción
de elementos materialistas como la utilidad instrumental (valor de
cambio), los recursos necesarios (acceso a las materias primas) y la
técnica (adquisición de conocimientos y desarrollo de habilidades). 
El desarrollo de las formas narrativas que consumimos a diario está sujeto a la ley de la empatía, en oposición a la abstracción. La empatía es la herramienta para materializar la aproximación naturalista; nos insta a establecer una relación de confianza entre el hombre y todos los fenómenos externos del mundo sensible, de tal manera que la pretensión de obtener una sensación de felicidad a través de la recepción de un producto artístico descansa en la capacidad de éste para reproducir la energía contenida en el espacio que recrea (Lipps, 1924). La inercia hacia la abstracción es diferente: hay que entenderla como el resultado de un gran malestar interior del hombre inspirado por los fenómenos del mundo exterior. La demanda de abstracción en el arte quedaría circunspecta a un inmenso temor espiritual al espacio, de ahí que éste quede suprimido, a la vez que confiere más importancia a descifrar el valor absoluto del objeto aislado de cualquier distracción (Worringer, 1997: 15; Riegl). Tomando el marco de la antropología evolutiva, el desarrollo biológico y social del hombre ha permitido la superación del miedo a los espacios abiertos (aprendiendo a subordinar la percepción de perderse), pasando a la colonización de éstos.

La colonización del espacio es uno de los dos grandes polos de la experiencia estética, pero también es uno de los pilares para la reproducción social. En el otro polo se haya la dialéctica entre el auto-goce y la auto-alienación (Raphael, 1968: 4-9). Con respecto a la segunda, tiene lugar cuando el proceso cognitivo percibe la vida real como una alteración del goce estético. Cuando el producto artístico es concebido como discurso político (determinado en gran parte por las condiciones materiales en la que es creado), aquel se convierte en un sustituto de la realidad (que queda ordenada), al mismo tiempo que el conocimiento de esta pasa a estar mediado en el consciente colectivo por una representación ideologizada (González Pascual, 2010). La evolución secular de las formas de representación audiovisual es un reflejo de la ideología eurocéntrica, dominada por el capitalismo cultural (que anestesia la demanda de abstracción). En ellas, emerge como constante la objetivación del mundo material que permite el uso del naturalismo como medio para justificar los aspectos formales de los derechos humanos, la participación democrática y los valores cristianos que organizan el culto en nuestras sociedades, lo que provoca que las líneas argumentales presentes en la producción cultural capitalista, alineadas con el consciente colectivo, tengan la pretensión de aparentar neutralidad en su relación con la parte de la realidad que es recreada como antagónica. Consecuentemente, la apariencia de mostrar esa realidad desde una perspectiva política caracterizada por la ecuanimidad, dando voz al otro y humanizando aquello que es extraño o diferente al canon jurídico y cultural de Occidente, se ha convertido en el recurso reiterado del posmodernismo actual, poniendo de manifiesto cuál es la psicología estilística ${ }^{13}$ del cine estadounidense contemporáneo, de la que es un perfecto referente la película de Greengrass.

La noción de neutralidad (como modalidad dentro de la "singularidad" conceptualizada por Jameson) puede significarse de dos formas: (I) Postura política libre de prejuicios y condicionamientos. (II) Práctica independiente de una actividad con respecto al hecho de estar al servicio de unos determinados intereses. En relación a la primera, se expuso ya cómo tiene lugar el proceso de enajenación para implantar la creencia de que las actitudes intelectuales, hábitos mentales $\mathrm{y}$ valoraciones racionales que mueven nuestra actividad contienen valores absolutos. En relación a la segunda, lo que se trasmite es la convicción de que el fin de la cultura dominante en Occidente es aumentar el bienestar del conjunto del mundo, lo que dicho de otro modo sería consagrar toda su motivación a la producción de

13 La psicología desgranada a través del "estilo" permite regular modificaciones en la reproducción que se hace de la vida sensible. Por consiguiente, es el umbral cognitivo que permite trascender la imitación para satisfacer la voluntad del artista, a la vez que el espectador sustituye crédulamente en su razonamiento la verdadera realidad por la creencia contenida en la reproducción de la realidad. 
conocimiento objetivo. Tales presupuestos articulan la psicología del estilo actual en el cine estadounidense, cuyo fin último es auto-activar un proceso de reacción en el espectador para negar cualquier diferenciación entre los intereses de su Yo y los intereses del modo de representar el mundo de una determinada manera. Esta estrategia facilita dejar oculta o muy en segundo plano la lucha de clases como tema narrativo para generar cambio histórico en las estructuras políticas y económicas recreadas.

\section{CONCLUSIONES FINALES: IDEOLOGÍA Y FORMA CINEMATOGRÁFICA}

En el apogeo de la revolución industrial británica, el teórico del arte John Ruskin practicó una lúcida crítica a la influencia que la división del trabajo capitalista estaba imponiendo sobre la producción artística y cómo, desde la superestructura, se estaba modificando la enseñanza de las artes en las escuelas, hasta el punto que en aquella época de liberalización, el espíritu mercantilista había logrado expandirse como la principal motivación social para mejorar en los conocimientos y en las habilidades necesarias para llegar a ser un artista reconocido. Ruskin se percató de que establecer tanto una enseñanza demasiado general como otra que fuera demasiado específica podía dar lugar al mismo tipo de ausencia de voluntad por trasformar la sociedad. Exigió moderadamente que se enseñara a los jóvenes en el análisis crítico de la naturaleza como objetivo prioritario para producir trabajadores para el arte $^{14}$ (lo que a la postre permitiría adquirir una conciencia de clase).

En el filme Capitán Phillips se percibe un simulacro por respetar este precepto de responsabilidad crítica bosquejado por Ruskin. Pero este queda traicionado al evaluar el resultado final: auto-engañado por la suficiencia de la moral eurocéntrica, el relato se limita a mostrar lo que el sistema capitalista es capaz de hacer para restablecer una anomalía, en vez de interesarse por mostrar aquello que el sistema es incapaz de hacer. El fracaso de la interpretación de Green- grass, desde la óptica de la dialéctica materialista, deviene por no saber dejar al descubierto todo aquello que existe en la naturaleza que no puede ser imitado, así como todo aquello que hay en el hombre que no puede ser sustituido. La consecuencia de su omisión es dejar el espacio liberado para creer que el valor de la vida humana puede quedar anulado (trasposición en la suerte que corren los secuestradores somalíes, como ocurrió en el hecho histórico, rescatando exclusivamente al plebeyo de la "República") de acuerdo a los principios valorativos de una comunidad humana que funciona en sincronía con las leyes unilaterales del modelo de acumulación del capital. Y es a través de tales leyes como el Centro (aunque sea desplazado geográficamente hacia otro Estado capitalista) ejerce su dominio sobre el curso de la historia habilitando la reproducción del ciclo sistémico de acumulación.

En la actual coyuntura se ha cumplido el pronóstico que hizo Fredric Jameson cuando, al analizar las alegorías políticas predominantes en la producción cinematográfica de los años setenta y ochenta, identificó que la mercantilización y la alienación, categorías de segundo orden en la tradición marxista del siglo pasado, pasarían al primer orden de prioridad para el interprete si es que se aspira a seguir practicando una crítica cultural seria y comprometida durante la expansión capitalista de nuestra época. La esfera económica se ha convertido en política cultural y esta, a su vez, ha subordinado tanto al resto de las dimensiones de la política como a las inclinaciones narrativas que pretenden captar el desarrollo histórico del género humano. Esta política cultural, con sus ambiguas fronteras, permite

14 "(...) no obtendremos resultados satisfactorios a menos que renunciemos a tal aspiración, proponiéndonos educar a los trabajadores con independencia de su tarea (...) educarlos, digo, hasta allá donde seamos capaces, en una única tara para todos; a saber, la Vista. Esto no es algo menor que enseñar: quizás sea en definitiva lo más importante que pueda llegar a enseñarse. Que te enseñen a leer ¿qué utilidad tiene cuando no puedes saber si lo que lees es verdadero o falso? Que te enseñen a escribir o a hablar ¿qué sentido tiene si no tienes nada que decir? Que te enseñen a pensar ¿qué sentido tiene si no tienes nada que pensar?". John Ruskin. "Discurso inaugural. Escuela de Cambridge" (1858) en La lámpara de la memoria (2014: 30). 
que la lógica de los procesos de producción de la economía evolucione sin apenas tener que atender problemáticas de parte tanto de productores como de consumidores.

La obsesión que transmite Greengrass en las últimas secuencias de la película, en las que son descritas las sofisticadas maniobras de los francotiradores, o el foco final en el estado emocional de Phillips cuando está siendo atendido por la oficial médica, son un fiel reflejo de la herencia de la modernidad en Occidente: el Primer Mundo vive obsesionado únicamente con la mejora del Primer Mundo, ofuscado por controlar las interacciones humanas, las relaciones sociales y las emociones del individuo aislado cuando este, aunque sea por casualidad, entra en contacto con las poderosas fuerzas ideológicas que marcan los significados de lo que es pertinente entender como inevitable: el "otro mundo" es solo un riesgo que amenaza la estabilidad del nuestro. La estética cinematográfica que acompaña a este ideologema (Jameson, 1989) se traduce en un aumento de la cobertura técnica de cada escena para demostrar la suficiencia política y económica del propio modelo que produce el texto cinematográfico. Por consiguiente, se trata de facilitar una cascada de opciones (como el uso de múltiples cámaras, el uso de la steadycam y el resto de utillaje audiovisual para suministrar un flujo abundante de material a la postproducción) para alcanzar el umbral máximo de la sorpresa sensorial. Sin embargo, el resultado nunca deja de ser un pastiche sobre otro pastiche, emergiendo la influencia que los filmes de John McTiernan durante los años ochenta y noventa tuvieron en el cine de acción posterior. Pero, en realidad, el mismo McTiernan siempre reconoció que su planificación multicámara y su edición impresionista procedía de copiar el estilo de montaje de The Wild Bunch y otros filmes violentos de los años sesenta (Bordwell, 2006). Greengrass intensifica ese mismo enfoque de realización aumentando el ASL (duración de los planos) hasta dejarlo en las secuencias de mayor intensidad dramática por debajo de los 3,8 segundos que se establecieron como promedio estándar para el género en los noventa y principios de este siglo (Salt, 2003 \& 2009). El efecto final consiste en dilatar el tiempo y el espacio para generar una tensión tan estresante que sea capaz de desencadenar en la consciencia del espectador el proceso de la desublimación represiva (González Pascual, 2010); un hallazgo que Greengrass experimentó con efectividad en su filme United 93 en 2006. No estamos, pues, ante una fase histórica que pueda llamarse "cinema postclásico", sino más bien en un manierismo ideológicamente condicionado por el historicismo teocéntrico que doctrinalmente se postula a sí mismo como el prisma verdadero desde el cual analizar y solucionar los conflictos internacionales y balancear la geopolítica occidental: una representación textual del "muro" para continuar legitimando la utilidad de separar el Primer Mundo del resto. 


\section{BIBLIOGRAFÍA}

AMIN, Samir. La ley del valor mundializada. Por un Marx sin fronteras, El Viejo Topo, España, 2011.

ALAVI, Hamza. Capitalism and Colonial Production: Essays on the Rise of Capitalism in Asia, Routledge Kegan \& Paul, Londres, 1982.

BATESON, Gregory. Pasos hacia una ecología de la mente, Lohlé-Lumen, Buenos Aires, 1998.

BLAUT, James M. The Colonizer's Model of the World. Geographical Diffusionism and Eurocentric history, The Guildford Press, New York, 1993.

BREMAN, Jan. The Labouring Poor in India: Patters of Exploitation, Subordination and Exclusion. Oxford University Press, Oxford, 2003.

BORDWELL, David. The Way Hollywood Tells It. Story and Style in Modern Movies. University of California Press, Berkeley, 2006.

CHANDRA, Bipan, The Writings of Bipan Chandra: The Making of Modern India: From Marx to Gandhi. Orient Blackswan, Nueva Delhi, 2012.

CHANDRA, Bipan. Rise and Growth of Economics Nationalism in India, People`s Publishing House, Nueva Delhi, 1966.

DAVIS, Mike. City of Quartz: Excavating the Future in Los Angeles, Vintage, Nueva York, 1992.

DAVIS, Mike. Más allá de Blade Runner. Control urbano: la ecología del miedo, Virus, Barcelona, 2001.

HALL, John A., Powers and Liberties: The Causes and Consequences of the Rise of the West, Penguin Books, Londres, 1989.

HARVEY, David. Espacios del capital, Akal, Madrid, 2009.

JAMESON, Fredric. Documentos de cultura, documentos de barbarie. La narrativa como acto socialmente simbólico, Visor, Madrid, 1989.

JAMESON, Fredric. La estética geopolítica. Cine y espacio en el sistema mundial, Paidós, Barcelona, 1992.

JUNG, Carl Gustav. Arquetipos e inconsciente colectivo, Paidós, Barcelona, 2012.

KOEPPING Klaus-Peter, Adolf Bastian and the Psychic Unity of Mankind. University of Queensland Press, Queensland, 1983.

GARCÍA FERNÁNDEZ, Emilio Carlos y SÁNCHEZ GONZÁLEZ, Santiago. Las imágenes de la historia en la obra de Stanley Kubrick. Cuadernos de historia contemporánea, Universidad Complutense de Madrid, Madrid, 2001.

GONZÁLEZ PASCUAL, Alberto. Ideología en el cine estadounidense 1990-2003, Fundamentos, Madrid, 2010.
GONZÁLEZ PASCUAL, Alberto. El pensamiento político de Fredric Jameson. Discurso utópico para transformar la realidad y la defensa del débil. Dykinson, Madrid, 2016.

IVERSEN, Margaret. Alois Riegl: Art History and Theory, MIT Press, Boston, 2003.

MARX, Karl. El Capital. Crítica a la economía política. Volumen I, Fondo de cultura Económica, México, 2001.

MARX, Karl y ENGELS, Friedrich. La ideología alemana, Akal, Madrid, 2013.

MONTEIL, Charles. Les Bambara du Ségou et du Kaarta étude historique, ethnographique et littéraire d'une peuplade du Soudan français, Larose, París, 1924.

LÉVY-BRUHL, Lucien. El alma primitiva. Península, Barcelona, 2003.

LIPPS, Theodor. Los fundamentos de la estética: la contemplación estética y las artes plásticas, Daniel Jorro, Madrid, 1924.

OBERAI, A.S. Population Growth, Employment and Poverty in Third World Mega-Cities, Palgrave Macmillan, Londres, 1993.

PARK, Robert E. y BURGESS Ernest W. The City: Suggestions for Investigation of Human Behavior in the Urban Environment, University of Chicago Press, Chicago, 1984.

RAPHAEL, Max. The Demands of the Art, Princeton University Press, New York, 1968.

RUSKIN, John. La lámpara de la memoria, Taurus, Madrid, 2014.

SALT, Barry. Film Style and Technology: History and Analysis, Starword, Londres, 2003.

SALT, Barry. Moving into Pictures, Starword, Londres, 2009.

WACKERNAGEL, Mathis. Rees, William. Notre empreinte écologique, EcoSociété, 2009.

WORRINGER, Wilhelm. Abstraction and empathy, Elephant, Chicago,1997. 